\title{
The Trend of Leprosy in Cebu Province, Philippines
}

\author{
JOSE N. RODRIGUEZ* \\ Philippine Division, American Leprosy Foundation \\ (l,eonard Wood Memorial)
}

\begin{abstract}
(1) Although covering different periods of time and different sections of the population, four studies are presented which establish the fact that there had been a downward trend of leprosy, at least of the lepromatous type, in the Province of Cebu, Philippines. (2) This decline occurred during a period when the administrative procedures for the control of leprosy consisted of compulsory segregation of bacteriologically positive cases and the out-patient treatment of pausibacillary cases at skin clinics. Moreover, the downward slope occurred during the pre-sulphone era. (3) Possible causes of the decline of leprosy in this Province are discussed.
\end{abstract}

From the time of the Spanish regime, it was common knowledge in the Philippines that the Province and Island of Cebu had the largest number of leprosy cases in the country. In fact there is historical reference to a large hospital for sufferers from leprosy built in 1854 by Bishop Romualdo Jimeno at the Carreta District, Cebu City, with the object of saving leprosy sufferers from begging in the streets. In a rapid survey made in 1896, the Medico-titular of the Province, Dr Rogel Lebres reported finding 426 cases in the city itself and estimated that there must have been more than 2000 leprosy sufferers in the Province at the time his survey was made.

The first attempt to determine the trend line of leprosy in Cebu was made by Rodriguez in 1936, using the method of least squares and based on the number of cases discovered annually from 1904 to 1934. The yearly number of discovered cases showed an insignificant downward trend $(a=222: 8 ; b=1.40)$.

In 1947, Doull et al. published an article in which they made use of historical inquiry as a method of estimating the trend of leprosy. The data which they used were collected from intensive surveys done in the towns of Cordova and Talisay, Province of $\mathrm{Cebu}$, and which had served as the basis of a number of previous epidemiological studies. A detailed history was obtained for every household studied, in some cases going back to the last few years of the preceeding century. Diligent efforts were made to include all births and deaths and all entrances into and departures from the household. At the same time, intensive inquiries were made as to the existence of leprosy in every individual in these two towns. Records on 3024 families were available, which included those of 21,791 individuals, varying in age from newly born infants to people more than 80 years of age. At the same time, all the living persons with leprosy were questioned, their

\footnotetext{
* Formerly Director of Disease Control, Department of Health, Republic of the Philippines.
} Received for publication 22 August, 1974. 
records in the leprosaria or skin clinics were analysed, and details about the history of the disease were obtained directly from members of the household and other observing persons in the $n$

bacteriologically negative cases were secured and sent to Dr H. W. Wade at Culion, for confirmation of the diagnosis.

During the period covered by this study, 402 cases of leprosy had occurred in these families. The data thus obtained permitted the use for the first time of a modified life-table method of analysis to determine the attack rate of the disease.

The authors arbitrarily divided the period of observation before and after 1 January, 1915, care being taken to select two groups of individuals in such a manner that the experience of the groups was mutually exclusive and limited to the same number of years. It was found that when the two periods, each covering a life-experience of 25 years, were compared, there was evidence of a downward trend as far as the incidence of the lepromatous type was concerned, the ratio of incidence rate for the earlier period to that of the latter being $2.0: 1$ for males and 2.4 : 1 for females.

The downward trend of the lepromatous type thus revealed by historical or retrospective method was subsequently confirmed on the basis of an actual study of cases undertaken in 1954 by Guinto et al. This study compared the prevalence and incidence rates of leprosy in the population of both towns and the attack rates in the household associates observed during the period between the initial and final surveys.

The combined prevalence for the lepromatous type at the preliminary survey averaged 11.6 per thousand of the enumerated population, while the prevalence rate as revealed by the final survey was 5.4 per thousand. On the other hand, the corresponding prevalence rate of the non-lepromatous types were 7.7 in the initial survey and 13.1 in the final survey. There was therefore a marked downward trend of the lepromatous type accompanied, by however, almost as marked an increase in the prevalence rates for the non-lepromatous type. This latter finding was viewed with concern by some leprologists who believed that a rise in the prevalence of the tuberculoid type may be the precursor to a serious increase later in the lepromatous type. Subsequent observations have established the fact that such fears were unfounded. As a matter of fact, there followed a decrease in the prevalence of the non-lepromatous cases.

Based on their data, the authors estimated also that during the two decades, between 1920 to 1940, the attack rate among the lepromatous type cases declined at an average of approximately 3\% annually, representing a decrease of the lepromatous type of $60 \%$ during the 20 year period.

In order to obtain data for the entire Province of Cebu, Rodriguez (1962) investigated the number of admissions (excluding re-admissions) of lepromatous cases from Cebu Province to all the leprosaria in the Philippines between 1907 and 1955, together with registered unsegregated cases found in Cebu from 1904 to 1906, and utilising the information already gained by Guinto et al. for Cordova and Talisay as a control.

During the first 26 year period, from 1904 to 1929, inclusive, there were 5290 recorded cases, compared to a total of 2882 recorded during the following 26 years (from 1930 to 1955 ) representing a reduction of about $46 \%$ during the latter 26 years, or a little less than $2 \%$ decrease per year. This is quite compatible with the $3 \%$ yearly reduction reported by Guinto et al. for Cordova and Talisay from 1920 to 1940 . 


\section{Discussion}

The four separate studies (Doull et al., 1947; Guinto et al., 1954; Rodriguez, 1936, 1962) which investigated the trend of leprosy in the Province of Cebu covered a period of half a century, from 1904 to 1955.

Starting from 1907, the administrative policy of the government regarding leprosy control consisted of "the apprehension, detention and segregation of bacteriologically positive lepers in the Culion Leper Colony". A modification of this Draconian measure was introduced in 1930 with the establishment of 8 regional leprosaria, officially called sanitaria, nearer to the homes of the patients, so that they could be visited frequently by their relatives and friends. The first local sanitarium was the Eastern Visayas Treatment Station, which later became the Eversley Childs Sanitarium built near Cebu City.

In 1952, following favourable results of trials with sulphone drugs in the leprosaria and skin clinics, Republic Act 753 was passed by Congress liberalizing the compulsory segregation law, to the extent of permitting home isolation of bacteriologically positive cases and consenting to their treatment by private physicians under certain conditions prescribed by the health authorities. The result of this step was rather unexpected. Very few patients already in the leprosaria applied for home isolation, perhaps foreseeing the socio-economic problems they would have to face in the outside world, and therefore preferring the security, assurance of medical care and food provided for them in the leprosaria. Moreover, there were only a few new cases who preferred isolation in their own homes to hospitalization in the leprosaria. Compulsory segregation was not abolished in the Philippines until 1964 with the enactment of Republic Act 4073 by Congress.

Thus during the entire period when leprosy was observed to show a decline in Cebu Province, the method of control employed by the government was that of the compulsory segregation of bacteriological positive cases either in leprosaria or in their homes, together with treatment of paucibacillary cases in stationary and mobile skin clinics.

Coincident with all these efforts to liberalize the segregation laws and to ameliorate the condition of the patients, an intensive educational campaign was undertaken using all media of communication, so as to inform the public about the true nature of the disease including its early manifestations and the necessity for early treatment. This led to voluntary presentation of many cases, including heavily bacillated ones, thus lessening to some extent the danger of public exposure to infective cases. Judging from this experience, it is felt that no leprosy control attempt can succeed without a well-planned enthusiastic and persistent educational programme to enlist public support.

As regards the treatment of leprosy employed in the Philippines during the period covered by these studies, the so-called Mercado mixture which contained chaulmoogra oil was injected to those who asked for it. During a period of 20 years (1922-1942) the standard anti-leprosy treatment consisted of systematic intramuscular and/or intradermal injections of improved chaulmoogra formulas, particularly the Iodized ethyl esters of $H$. wightiana oil (WEI).

Some authorities may view the results of chaulmoogra preparation with scepticism, but there can be no question as to the accuracy of the clinical and bacteriological examinations which were undertaken by a local "Negative Committee" in each leprosarium whose findings were reviewed in turn by a 
mobile National Disposal Committee. No negative case was released unless it remained continuously negative for 2 years. However, re-examination of small sample groups of such released negatives showed a high relapse rate of about $40 \%$ in 5 years.

No explanation can be given regarding this apparent result of chaulmoogra treatment in the Philippines during the period studied. It may be suspected that a considerable number of "open" cases admitted to the leprosaria at that time were probably Borderline and reacting Tuberculoid cases which according to the experience of many leprologists could either subside spontaneously or respond favourably to chaulmoogra treatment. The proportion of such cases was probably not high, especially during the second half of the period under review, because Filipino leprologists became familiar with the diagnosis of such cases through the investigations in Cebu of Rodriguez and Wade, whose results were published in a series of articles in the International Journal of Leprosy between 1935 and 1940.

After the termination of World War II in the Pacific in 1945, WEI continued to be the standard leprosy treatment in Cebu, as the new sulphone drugs were not available in sufficient amounts in the country, although they did gradually supplant the chaulmoogra preparation in all the sanitaria and clinics. Mass treatment with dapsone did not become routine until the establishment of the Cebu Skin Clinic in 1955. Thus, the downward trend of leprosy took place before sulphone treatment was fully introduced.

In view of all the above considerations it is reasonable to surmise that the administrative measures and the technical procedures employed were at least partly responsible for the downward trend of leprosy in the Province of Cebu, although it was realized earlier, in the implementation of the Pilot Leprosy Programme in this Province that the roles of other factors, such as the socio-economic status, diet, health and educational standard of the general population are also important. For this reason, in conducting the continuous epidemiological surveys in Cordova (Doull et al., 1936), Talisay (Guinto et al., 1941 ) and Santander (Guinto and Rodriguez, 1941) diligent efforts were made to obtain data on which could be based some approximation as to the possible effects of environmental factors on the spread of leprosy. A fourth town, Opon (Rodriguez and Plantilla, 1934) was also specially surveyed for this purpose.

As shown in the articles referred to under condition obtaining in the towns surveyed, it was next to impossible to obtain even approximate figures for this purpose. For instance, in order to obtain data on the income of each family, the first step taken was to determine the occupation of the head of the family, but it was found out that most of them were part fishermen and part farmers in varying degrees. It was necessary to resort to the expediency of giving arbitrary estimates of income derived from fishing by hand, net or trap. On the other hand, the farming income was estimated by counting banana plants, and estimating heads of corn harvested from the small stony lots. Furthermore, the yield was consumed by the family and little of it, if any, was ever sold, so there was no cash income to record.

It is true however, that in many countries, it had been established that such extrinsic factors as socio-economic advancement, diet and proper health habits are important determining factors among others in the spread of tuberculosis, and it is generally accepted that these factors should have a similar effect in the case of leprosy.

However, relative to this question, a unique experience was brought to light by 
the epidemiological studies in Cebu. This concerns the small town of Cordova. In this town, the economic condition of the population has steadily retrogressed compared to their original status in 1933. At that time, the community received a modest income derived from planting of maguey, from which was derived a fibre used for rope making which had a ready market; but the commercial demand for this fibre collapsed in the early 1940s. Fishing, which used to be another source of income as well as of food supply, had been greatly'depleted, due to the use of dynamite fishing, chiefly done by people from other towns. Problems of living in this town were made more acute by a population explosion which propelled the number of its inhabitants from 6063 in 1933 to 10,904 in 1966.

All these factors naturally had their impact on the health of the people. They continued to be as malnourished as they were 36 years previously, judging from poor nutrition, low body weights, and the prevalence of such conditions as Pellagra, nicteralopia, and other concomitants of avitaminosis and malnutrition. Nevertheless the downward trend of leprosy continued in this town in spite of these unfavourable extrinsic factors which affected the entire community. This totally unexpected finding is difficult to explain. However, this experience is based on a single small area and does not necessarily apply to other towns in the Province and the rest of the country. In my opinion, it is one more indication that perhaps there are other factors surrounding the contagiousness of leprosy that are not known to us at the present time. An intensive survey of the town of Santander in Cebu Province undertaken by Guinto and Rodriguez (1941) in 1938, confirmed the fact that leprosy had been introduced in this town, but the disease had not spread in spite of the fact that it is inhabited by the same people as the other towns surveyed who were enjoying the same socio-economic status, were eating the same food and had the same health habits. The investigators were not able to explain why leprosy had not been able to obtain a foothold in Santander as it had in Cordova, Talisay and Opon.

\section{References}

Doull, J. A., Rodriguez, J. N., Guinto, R. and Plantilla, C. (1936). A field of study of leprosy in Cebu, Int. J. Lepr. 4, 141-169.

Doull, J. A., Guinto R. S. Bancroft, H. and Rodriguez, J. N. (1947). Historical inquiry as a method of estimating the trend of leprosy. Int. J. Lepr. 15, 369-375.

Guinto, R. S. and Rodriguez, J. N. (1941). A field of study of leprosy in Talisay, Cebu, Philippines. Int. J. Lepr. 9, 149-196.

Guinto, R. S. and Rodriguez. J. N. (1941). A leprosy survey of a control area in Santander, Cebu, Philippines 9, 315-325.

Guinto, R. S., Rodriguez J. N., Doull, J. A. and de Guia, L. (1954). The trend of leprosy in Cordova and Talisay, Cebu Province, Philippines. Int. J. Lepr. 22, 409-430.

Rodriguez, J. N. and Plantilla, F. C. (1934). Leprosy in Cebu II. Philippines. J. Sci. 58, 1-46.

Rodriguez, J. N. (1936). Our leprosy problem in the Philippines. Monthly Bulletin of the Bureau of Health 16, 161-179.

Rodriguez, J. N. (1962). Evaluation of the leprosy control program of the Philippines. Int. J. Lepr. 30, 111-124. 